\title{
How do tourists look at Sintra's world heritage?
}

\author{
H. Roque, M. Henriques \& H. Mouriño \\ Department of Statistics and Operational Research, \\ Faculdade de Ciências, Universidade de Lisboa, Portugal
}

\begin{abstract}
In December 1995, Sintra was included on the World Heritage List under the name of "The Cultural Landscape of Sintra". This classification is related with the pioneering role played by Sintra in the $19^{\text {th }}$ century in establishing the European Romantic architecture. The UNESCO World Heritage Site designation has substantially increased visitors flow to Sintra. For instance, in August 2010 about 240,000 persons visited the Palaces and Parks of Sintra. One of the main challenges that local policy-makers are faced with is how to effectively deal with the main impacts of the Sintra's World Heritage status, especially in what concerns to mass tourism. It urges policy-makers to implement sustainable tourism. Hence, it becomes crucial to fully understand what tourists think about Sintra's World Heritage. To this purpose, in August and September 2010, a survey was conducted to the tourists that visited the Palaces and Parks of Sintra. We found out that tourists are eager to visit Sintra mainly because of its Classification as a World Heritage site. The majority of the tourists consider that the state of preservation of the Palaces and Parks is "Good" or "Very good". Nevertheless, the renovation and conservation of the urban area in the historic centre are required. For the majority of tourists, Sintra is a place for a one-day visit. Hence, it is important to develop a more effective marketing strategy to attract visitors to Sintra for more than just one day.

Keywords: Sintra, world heritage site, survey study, Kruskal-Wallis test.
\end{abstract}

\section{Introduction}

Situated in the district of Lisbon, the old town of Sintra and its natural surroundings - composed of hundreds of trees and exotic flowers within unique 
gardens, parks and forests - are one of the most emblematic places in Portugal. In 1995, the Serra and Town of Sintra were inscribed on the World Heritage List under the name "The Cultural Landscape of Sintra". It is considered a unique place in the world due to the complexity and characteristic symbiosis between the natural and the built heritage. The parks, gardens, palaces, country houses, monasteries and castles, which creates a popular and cultural architecture, harmonises with the exotic and overgrown vegetation, creating micro-landscapes of exotic and luxuriant beauty (ICOMOS [1]). The site has been considered of outstanding universal value as it represents a pioneering approach to Romantic landscaping which had an outstanding influence on developments elsewhere in Europe (WHC [2]).

World Heritage Site status has become a measure of quality assurance, a trademark and an "authenticity stamp" for the heritage tourism and an arena for the presentation of prestigious national heritage (Rakić and Chambers [3]). Some authors believe that a site's inscription on the World Heritage List often coincides with a boost in visitation rates (Pedersen [4]). Having in mind that nowadays tourism is one of the most dynamic industries, it is vital for managers to attain the right balance between economic expansion due to the increase of the number of visitors and the undesirable impacts associated with tourism growth. This is becoming evident in popular tourist sites and often in unique and fragile environments such as World Heritage sites (Gilmore et al. [5]). Additionally, managers know that a tourist attraction must be periodically renewed to remain competitive, but at the same time the World Heritage sites are obliged to maintain or restore its original values. This responsibility poses difficult questions regarding the degree of change that should be permitted to accommodate tourism growth (Pedersen [4]).

To meet these and other challenges, managers and local authorities must deeply understand what tourists think about the sites as well as their expectations. Furthermore, it is important to get some insights into visitor's profile. This strategy will certainly help managers and local authorities in implementing more effective promotion policies and developing accurate visitor management strategies. It can also shed some light on establishing policies for settings of entrance fees because we can measure visitors' willingness to pay. In this context, the tourist's survey plays a crucial role.

In the last decades, there has been a widespread of the tourists' surveys focused on heritage places and also on World Heritage sites. The main goal of some of these studies is to identify demographic and travel behaviour of the tourists that are keen on this type of destinations. There is also an attempt to investigate the relationship between the attributes of these places and tourist satisfaction. Huh [6], analysed tourists' behaviour in the Virginia Historic Triangle, which has been called the "largest living museum in the World". He found out that women are more satisfied than men. Additionally, tourists with previous experience with heritage destinations were more satisfied than the others. The study also revealed that the tourism planners should focus more on available accommodation and accessibilities to meet tourists' expectations. Huh [6], stated that to create effective marketing strategies for products and services 
in this type of markets, a better understanding of tourists who visit these destinations is necessary. Silberberg [7], outlined the characteristics of the cultural/heritage tourist in Canada and the United States: earns more money and spends more money while on vacation; spends more time in an area while on vacation; is more likely to stay at hotels or motels; is far more likely to shop; is more highly educated than the general public; includes more women than men; tends to be in older age categories. Prayag [8], examined the relationship between destination image, satisfaction and future behavioural intentions of visitors to the island of Mauritius. Several recommendations were made on the importance of destination image and specific image attributes that generate favourable word-of-mouth recommendations and revisit intentions. In a slightly different perspective Poria et al. [9], researched visitors' preferences for interpretation at the Wailing Wall in Jerusalem, a religious heritage site. Interpretation is a very important factor in the visit experience. One of the main finding was that the more participants regard the site as part of their personal heritage, the more interested they were in having the interpretation focus on their heritage (Poria et al. [9]).

The discussion raised above highlights the need for developing similar studies focusing on Sintra's World Heritage. It is worth mentioning that Sintra is one of the most important tourists' attractions in Portugal. For instance, in August 2010 about 240 thousand people visited the Palaces and Parks of Sintra, which was approximately $9 \%$ of Portugal's total number of tourists in that month, according to tourism data from Statistics Portugal. Thus, it becomes crucial to listen to tourists' opinion about Sintra's World Heritage. Until now, a study with these characteristics is missed from the existing literature. This study attempts to narrow the gap that exists in literature and corresponds to a pioneering approach to the problem at hand.

The main goal of this paper is to examine to what extent tourists are satisfied with this heritage site and whether their expectations are fulfilled. Tourists will also be asked to evaluate the state of conservation of the palaces and parks. Moreover, we will attempt to outline the main characteristics of the tourists that are keen on this place. To attain this goal, we will analyse some of the commonly used demographic, socioeconomic and behavioural variables in tourism research, that is, gender, age group, reasons for choosing Sintra, length of stay, academic qualifications, nationality, past experience with this destination, etc.

In order to attain the objectives just cited, a tourist's survey was conducted at Sintra's World Heritage during August and September 2010. Data were collected through face-to-face structured interviews at the entrance to the most emblematic parks and buildings and also in the historical center of Sintra. Participants were randomly selected and were at least 18 years old. A total of 370 tourists were interviewed, but 10 questionnaires were excluded due to missing data.

The paper proceeds as follows. The tourist's survey is provided in Section 2. The most relevant results from data analysis are provided in Section 3. Finally, Section 4 is dedicated to the main conclusion and suggestions for future research. 


\section{A survey: tourist's opinion about Sintra}

The aim of this paper is to analyse how tourists look at Sintra' World Heritage. As a consequence, we need to develop a tourist's survey. So far, there has been no literature addressing this issue and we were thus compelled to develop a procedure for obtaining this type of primary information: tourist's questionnaire. In this section, an outline of the tourist's survey is provided. Section 2.1 is dedicated to the description of the sampling design. An overview of the questionnaire is given in Section 2.2. Lastly, a summary of the main statistical tools used to analyse the sample data is provided in Section 2.3.

\subsection{Sampling design}

In August and September 2010, an on-site survey to the tourists that visited the Palaces and Parks of Sintra was conducted. The survey consisted of a structured questionnaire and its main goal was to evaluate how tourists look at Sintra's World Heritage. Furthermore, we would like to analyse the relationship between tourists' profile and their overall satisfaction with this heritage site.

The sample was composed of tourists that visited the palaces, convent or castle that are classified as World Heritage by the Decree-Law No. 93 March 23, 1999: Castelo dos Mouros; Convento dos Capuchos; Palácio de Monserrate; Palácio Nacional da Pena (including the park); Palácio Nacional de Sintra; Palácio da Regaleira; Palácio de Seteais (including the gardens). We also interviewed tourists in Sintra's town centre, hereafter called Vila de Sintra.

Tourists were approached at the entrance of the buildings and also in the Vila de Sintra for answering to the questionnaire. They were informed about the aims of the survey and also about the length of the questionnaire, which took roughly ten minutes to fill in. Additionally, respondents were assured that their responses would remain anonymous. The inquiries took place at different days of the week, including weekends. The field work was carried out during daytime between 11 A.M. and 8.30 P.M. Tourists over 18-years-old were selected at random and no effort was made to select particular segments of the population.

The field work started on August 9th 2010, with the pilot questionnaire. The pilot sample size was approximately $10 \%$ of the main sample size (Chisnall [10]). The pilot testing of the questionnaire revealed that only slight changes were needed: a few multi-choice questions were changed to simple alternative questions as tourists were unable to evaluate the attribute under consideration in a rating scale; some questions were rewritten because their meaning were not clearly understood by non-Portuguese tourists. The main sample was collected from August 12th until the end of September. We obtained a final sample of 370 respondents, from which we eliminated 10 questionnaires due to missing values.

\subsection{The tourist questionnaire}

The face-to-face interview consisted of a structured questionnaire with thirty nine questions. There were only three open questions, where tourists could express their feelings, suggestions and complaints about Sintra's World Heritage 
in general. The results of these questions are not reported here. Henceforth, we will only focus on the closed questions. The closed questions were either simple alternative questions or multi-choice questions. Tourists were asked to respond to each multi-choice question using a five-point Likert-type scale ranging from 1 (very unfavourable opinion) to 5 (very favourable opinion).

The questionnaire was composed of seven main sections: reasons for visiting Sintra and duration of stay; transportation to and in Sintra; activities in Sintra; regional products; evaluating Sintra's World Heritage; knowledge about the beaches in the neighbourhood of Sintra; personal details of the respondent.

In this paper, we will focus on tourist's satisfaction with this heritage site and tourist's profile. Tourist's satisfaction includes: state of conservation of the buildings and parks cited in Section 2.1; evaluation of the entrances fees; overall satisfaction with this heritage site; intention to return; etc. Tourist's profile includes: gender; age; academic qualifications; employment status; nationality; past experience with this destination; duration of stay; main reasons for choosing Sintra. Some of these topics will be analysed in detail in Section 3.

\subsection{Statistical analysis}

Several statistical analyses were performed to the sample data. Special emphasis was given to the exploratory data analysis. In order to study the influence of tourists' profile on the general satisfaction with the visit to Sintra, the KruskalWallis test was computed (Sprent [11]; Conover [12]). When the null hypothesis on identical behaviour of the different populations under study was rejected, multiple comparisons tests were performed. The idea was to determine which pairs of the populations tended to differ (Conover [12]). The results from the statistical tests were evaluated using the $1 \%$ significance level as the threshold for distinguishing between "not statistically significant" and the opposite. It is worth stressing that the results of some of these tests will not be reported here.

\section{Main results}

\subsection{Tourist's profile}

Based on the 360 questionnaires collected at Sintra's World Heritage, we verified that the gender distribution was quite even because $49 \%$ were men and $51 \%$ were female. The predominant age group was between $26-39$ years $(36 \%)$, followed by 40-50 years (24\%), 51-64 (18\%), 18-25 (14\%) and finally the group with least representation - greater than or equal to 65 years old $(8 \%)$.

Considering the education level, the majority of the tourists $(67 \%)$ had a university degree, $21 \%$ had high school degree, $6 \%$ had primary education and $6 \%$ had professional certification. Sintra is known as a town of palaces, full of culture and history. This characteristic might attract high educated tourists.

Regarding the employment status, the majority of the respondents had a professional activity $(73 \%)$, followed by students and pensioners $(11 \%$ for each 
category). Finally, the unemployed represent $3 \%$ of the respondents and $2 \%$ of the respondents were housewives or house husbands.

Figure 1 displays the percentage of respondents by nationality. We verify that the majority of the respondents were Portuguese $(40 \%)$. Also, $22 \%$ of the respondents came from Spain. Thus, about $62 \%$ of respondents who visited the Vila de Sintra had their origins in the Iberian Peninsula. This might be due to the strong relationship that exists between these two countries, which contrasts with what happens elsewhere in Europe. Additionally, 19\% of the respondents came from the Central Europe, with special emphasis to France and Germany. It is worth mentioning that $82 \%$ of the foreign tourists came from Europe.

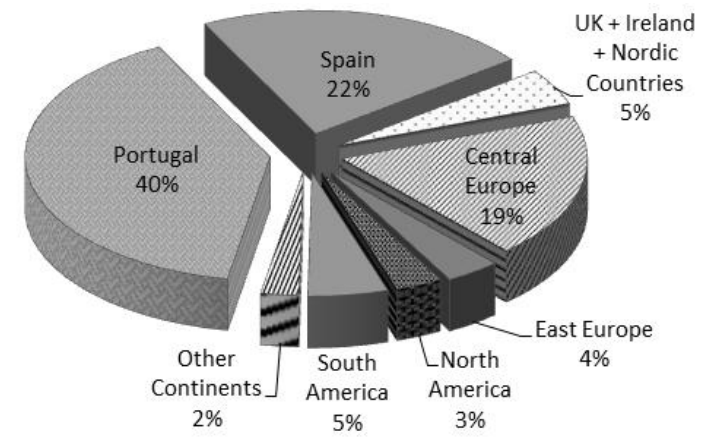

Figure 1: Percentage of respondents by nationality.

Considering the past experience with this destination, for $54 \%$ of the respondents it was the first time that they came to the Vila de Sintra, whereas $46 \%$ of the visitors had already visited Sintra before. Of the 167 people who had already visited Sintra, the majority (54\%) had been to this place more than ten times, $25 \%$ had visited Sintra between three and five times and $21 \%$ between one and two times. It must be emphasised that $42 \%$ of the people that visited Sintra more than 10 times are tourists who live near Sintra or even in the municipality of Sintra.

For the vast majority of the respondents, Sintra is a place for a one day tour $(89 \%)$. With regard to the length of stay for the remaining tourists, $7 \%$ stayed for two days and $2 \%$ stayed between three and five days. Also, $2 \%$ of the respondents stayed six days or more. Considering the destination of the trip, Figure 2 reveals that $47 \%$ of respondents specifically wanted to visit the town of Sintra, whereas $34 \%$ of the respondents had arranged a trip to Lisbon. For $17 \%$ of the respondents, the trip's destination was Cascais/Estoril and for $2 \%$ of the respondents the destination of the trip was elsewhere in the country. Another important result is that $86 \%$ of the respondents that had arranged a trip to Sintra were only one-day visitors (Figure 2). Making a connection between these results and the nationality, we think that the fact that there were so many Portuguese tourists in the sample (40\%) might have led to the unexpected result that roughly half of the respondent had arranged a trip to Sintra. 


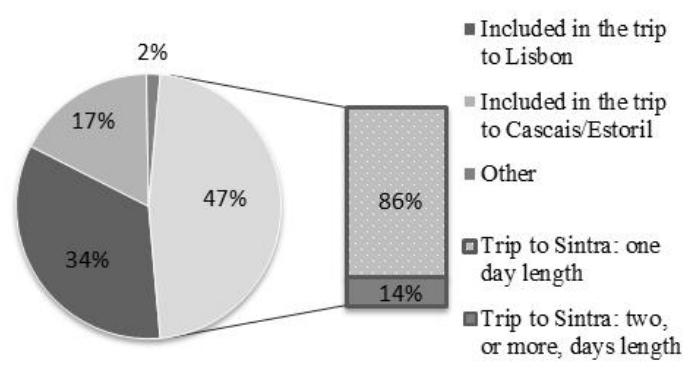

Figure 2: Destination of the trip: percentage of respondents falling in each category.

Summing up, the results show that most people who visit Sintra see it as a one day tour. One of the biggest problems of Sintra is related with the short duration of stay, which reduces the economic benefits for the local communities. Tourists are not aware of the great potentialities of Sintra in terms of tourism and they still think that this tourist destination is just an easy daytrip from Lisbon or Cascais/Estoril. Much needs to be done to promote Sintra as a tourist destination itself. In particular, managers and local authorities should develop accurate strategies for increasing the length of stay in Sintra. They should emphasise the unique experience of feeling the Sintra's magical atmosphere at night.

Figure 3 shows the reasons for visiting Sintra. Having in mind that it was a multiple response question, the percentage of respondents who selected each item (out of a total of $n=360$ enquiries, for each item) is displayed in the graphic. The most relevant reasons are, thus, the following: holidays/leisure (84\%); the World Heritage status (66\%); previous visits to this tourist destination (31\%).

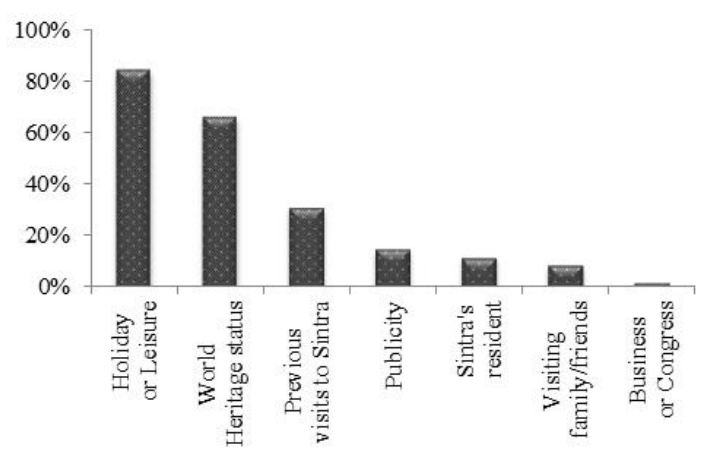

Figure 3: $\quad$ Reasons for visiting Sintra.

These analyses emphasise the idea that Sintra is a popular tourist destination because the vast majority of respondents travel to Vila de Sintra on vacation. 
Also, it seems that the designation World Heritage Site can be an effective brand. In third place we have the past experience with this heritage site. From these results, it seems that people are keen on returning several times to Sintra in order to savour the pleasures of this beautiful town. This point will be analysed further in Section 3.2.

\subsection{Sintra's world heritage: state of conservation. Global evaluation}

In this section, the main results from the evaluation of Sintra's World Heritage are provided.

Tourists were questioned on the fees charged for admission to the heritage buildings and parks. They were presented with the following question: "On the overall, what do you think about the entrances fees at the palaces, castle, convent and parks?" The answer was given on a 5-points Likert scale, ranging from 1 (Very Expensive) to 5 (Very Cheap). The results show that almost half of the respondents $(48 \%)$ considered that the entrances fees were neither cheap nor expensive. Also, $46 \%$ of the respondents said the admission fees were expensive or very expensive. The remaining $6 \%$ of the respondents said that the entrance fees were cheap or very cheap.

Tourists were questioned on the state of conservation of the buildings (that is, palaces, castle, and convent) as well as the parks. They were asked to report on the level of agreement on a 5-point Likert scale ranging from 1 (Very Bad) to 5 (Very Good). In regard to the conservation of the palaces, castle and convent, the majority of the respondents (72\%) considered that their state of conservation is "Good" or "Very Good". Only 2\% of the respondents said that the buildings were in poor conditions. In order to analyse if tourists' opinion depends on their profile, a few Kruskal-Wallis tests were performed. The variables under consideration were: gender; academic qualifications; employment status; age group; nationality. The results indicate that no significant differences in tourists' opinion on the state of conservation of the heritage buildings was found by gender (test statistic $=2.08 ; \mathrm{p}$-value $=0.15$ ), employment status (test statistic $=3.01$; $\mathrm{p}$-value $=0.56$ ); age group (test statistic $=3.70 ; \mathrm{p}$-value $=0.45$ ) and nationality (test statistic $=7.18 ; \mathrm{p}$-value $=0.41$ ). However, tourist's opinion on the state of conservation of the heritage buildings depends on its academic qualifications (test statistic $=12.55 ; \mathrm{p}$-value $=0.01$ ). In view of this conclusion, multiple comparisons tests were performed. We found out that tourists with primary education behave differently from those with university degree (test statistic $=2.89$; $\mathrm{p}$-value $=0.00$ ). It is worth stressing that $77 \%$ of the tourists with university degree considered that the state of conservation of the heritage buildings was good or very good. In regard to tourists with primary education, this percentage decreased to $48 \%$.

In relation to the parks, the large majority of the tourists $(86 \%)$ considered that their state of conservation was "Good" or "Very Good".

Tourists were asked how safe they felt in this tourist destination. This attribute was measured on a 5-point Likert scale. For the large majority of the tourists $(94 \%)$, Sintra was a safe or very safe place to visit. For the remaining tourists, Sintra was neither safe nor unsafe. 
Tourists' overall level of satisfaction with Sintra was measured on a 5-points Likert scale, ranging from 1 (Very Weak) to 5 (Very Good). The results are very promising, as $91 \%$ of the respondents gave a "Good" or "Very Good" classification to Sintra. Moreover, $7 \%$ of the tourists classified Sintra as "Reasonable" and only $2 \%$ of the respondents gave a weak classification to this town. Despite obtaining good results in this question, a few tourists (about 5\%) claim that renovation and conservation of the urban area in the historical town centre are required. In order to examine the overall satisfaction by tourist's profile, a few Kruskal-Wallis tests were computed. The results indicated that no significant differences in the overall satisfaction of the respondents were found by gender (test statistic $=0.14 ; \mathrm{p}$-value $=0.71$ ), employment status (test statistic $=3.56 ; \mathrm{p}$-value $=0.47$ ); age group (test statistic $=1.71 ; \mathrm{p}$-value $=0.79$ ); academic qualifications (test statistic $=1.44 ; \mathrm{p}$-value $=0.70$ ). Nevertheless, the overall satisfaction depends on tourists' nationalities (test statistic $=19.72$; pvalue $=0.01$ ). In order to understand the effect of each nationality on the overall satisfaction, a few multiple comparisons tests were performed. We concluded that Portuguese and North Americans differ on the level of satisfaction with Sintra (test statistic=2.95; p-value=0.00). Similar situations happen when comparing Spanish tourists with those from Central Europe (test statistic=2.63; $\mathrm{p}$-value $=0.01)$. Moreover, the overall satisfaction of tourists from North America is different to those from Central Europe (test statistic $=3.71$; p-value $=0.00$ ). For instance, $46 \%$ of the Portuguese tourists gave a very good classification to Sintra. This percentage doubled for the North Americans (91\%).

With regard to expectations with the visit to the town of Sintra, $68 \%$ of respondents said it was according to expectations and 30\% said that it was above expectations. Only $2 \%$ of the respondents said that the visit was below their expectations. Another interesting result was that $93 \%$ of respondents would like to return to the town of Sintra in the future. The reason for so high percentage might be related with the following comment "I have never thought there were so many heritage buildings in Sintra. I would like to return in order to visit those buildings that I have not had the opportunity in this trip". The remaining $7 \%$ of the tourists said that there are so many interesting places to visit in the World that they would not like to return to Sintra. Nevertheless, $99.7 \%$ of the respondents would recommend this tourist destination to a friend. Summing up, Sintra is a very attractive place to visit. It seems that it is the rich cultural and natural heritage that makes Sintra such a popular tourism destination.

\section{Conclusions and future research}

Sintra is one of the most famous tourists' destinations in Portugal. In 1995, it was added to the World Heritage list under the category "World Heritage Cultural Landscape", which was a global recognition of its uniqueness. It is worth mentioning that only about $7 \%$ of the total World Heritage sites are inscribed under this category, which clearly reveals the emphasis placed by UNESCO on Sintra's charming and mysterious environment. 
The unique characteristics of places like Sintra make them an attractive destination for the tourism industry, which is one of the major engines of today's global economy. Managers and local authorities are, thus, faced with the great challenge of overcoming the negative impact of tourism on World Heritage sites. We should not forget that the World Heritage convention relies on the principle that World Heritage sites belong to everyone and should be preserved for future generations. This goal can only be achieved with sustainable policies.

Negative tourism impacts are caused mainly by development and visitors themselves. In order to help managers and local authorities in developing accurate sustainable tourism policies, it is crucial to examine how tourists look at a World Heritage site like Sintra as well as the extent to which their expectations are fulfilled. Moreover, an evaluation of tourists' profile will certainly be very useful for managers and local authorities in developing more efficient visitors' policies. This paper aimed at shedding some light into these issues by developing a tourist's survey. Studies of this nature have already appeared in the specialised literature but no one has ever analysed the case of Sintra.

The face-to-face structured interviews were conducted in the summer of 2010 to the visitors of the Sintra's World Heritage. The main findings of this pioneering research can be summarised as follows. Tourists who visit Sintra are mainly young adults with university education. Women are as keen as men on visiting this heritage site. As expected, the majority of tourists come from the Iberian Peninsula with roughly the following distribution: two-thirds of the tourists are Portuguese and one-third come from Spain. The majority of tourists had never been to Sintra before. Moreover, the majority of tourists have only one day to spend in Sintra. This is one of the most problematic issues that managers and local authorities have to handle in a more effective way in the future. The World Heritage designation is an effective brand because for the majority of tourists this is one of the reasons for their visit.

An overview of this heritage site can be summarised as follows: Sintra is considered a safe place to visit; the majority of tourists consider that the heritage buildings, the parks and gardens are well preserved; there is no consensus about the entrances fees because roughly half of tourists find the prices of admission expensive or very expensive, whereas the remaining ones find it neither cheap nor expensive. Concerning the overall level of satisfaction with this heritage site, the large majority of tourists give a "good" or "very good" classification to Sintra. Nevertheless, it is worth stressing that some of them emphasise the need to renovate the urban area in the Vila de Sintra. For the large majority of tourists, Sintra is according or above the expectations and they will recommend this tourist destination to a friend.

An important feature that has not been studied in this research is the impact of the World Heritage status on the host community. Several authors have left these issues out of their research because they assume homogeneous communities, which usually do not fit real-life neighbourhood connections. In particular, for World Heritage sites like Sintra there is also a great interest in analysing the degree of commitment of local communities to safeguard their historic, cultural and natural resources. A few studies have appeared in literature about this 
subject. For instance, Nicholas et al. [13], examined the factors that influence local community residents' support for designation and sustainable tourism development in the Pitons Management Area, Santa Lucia. An interesting result was that the more attached residents are to their community the more supportive they will be of developing tourism in a sustainable manner in this area.

Further development of the present research should evaluate how the local communities look at the visitors coming to Sintra. It will be important to verify if residents and community associations are aware of the need to implement sustainable tourism policies for preserving the cultural landscape for future generations. Additionally, it will be very interesting to analyse to which extent residents are keen on sharing the mixture of history, fairy tales, and traditions of this enchanting place with tourists.

This type of commitment of local communities to tourism issues will certainly be a step ahead for them to be more active in getting involved in other questions related with heritage tourism. In a slightly different perspective from that presented above, but perhaps even more relevant in terms of protecting the property, stakeholders must listen to Sintra's local communities about positive and negative impacts of various management strategies. This procedure will certainly give a great help in preserving the attributes of the Outstanding Universal Value of Sintra. The World Heritage Committee refers that the municipality and the remaining stakeholders need to recognise the importance of motivating the local communities in the process of managing the property (WHC [14]). We believe that this type of strategy will compel the municipality to be more dynamic in safeguarding the property from fierce economic growth and urban development in Sintra.

\section{References}

[1] The International Council on Monuments and Sites (ICOMOS), Advisory Body Evaluation - World Heritage List: Sintra, No. 723, pp.53-63, September 1995.

[2] World Heritage Committee (WHC), Convention Concerning the Protection of the World Cultural and Natural Heritage, Nineteenth Section, Berlin, Germany, pp. 48, December 1995.

[3] Rakić, T. and Chambers, D. World Heritage: exploring the tensions between the national and the 'universal', Journal of Heritage Tourism, 2(3), pp. $145-155,2007$.

[4] Pedersen, A., Managing Tourism at World Heritage Sites: a Practical Manual for World Heritage Sites Managers, UNESCO World Heritage Centre, France, pp.22-27, 2002.

[5] Gilmore, A., Carson, D. and Ascenção, M., Sustainable tourism marketing at a World Heritage site, Journal of Strategic Marketing, 15(2-3), pp.253264, 2007.

[6] Huh, J., Tourist Satisfaction with Cultural/Heritage Sites: The Virginia Historic Triangle, Thesis submitted to the Faculty of the Virginia Polytechnic Institute and State University, Master of Science, March, 2002. 
[7] Silberberg, T., Cultural tourism and business opportunities for museums and heritage sites, Tourism Management, 16(5), pp.361-365, 1995.

[8] Prayag, G., Tourists' Evaluations of Destination Image, Satisfaction, and Future Behavioral Intentions - The Case of Mauritius, Journal of Travel \& Tourism Marketing, 26(8), pp.836-853, 2009.

[9] Poria, Y., Biran, A. and Reichel, A., Visitors' Preferences for Interpretation at Heritage Sites, Journal of Travel Research, 48(1), pp.92-105, 2009.

[10] Chisnall, P., Marketing Research, $7^{\text {th }}$ edition, McGraw-Hill Education: England, pp.149-151, 2005.

[11] Sprent, P., Applied Nonparametric Statistical Methods, Chapman \& Hall: Great Britain, pp.209-243, 1993.

[12] Conover, W. J., Practical Nonparametric Statistics, Third Edition, John Wiley and Sons: New York, pp.269-300, 1999.

[13] Nicholas, L. N., Thapa, B. and Ko, Y. J., Residents' Perspectives of a World Heritage Site - The Pitons Management Area, St. Lucia, Annals of Tourism Research, 36(3), pp.390-412, 2009.

[14] World Heritage Committee (WHC), United Nations Educational, Scientific and Cultural Organization - Convention Concerning the Protection of the World Cultural and Natural Heritage, World Heritage Committee, Thirtyfourth Session, Brazil, 2010, WHC-10/34.COM/20. 